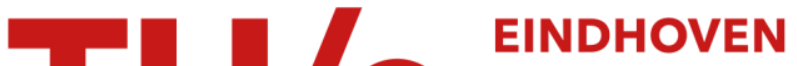 UNIVERSITY OF TECHNOLOGY
}

\section{Chemical composition distribution of styrene-methyl acrylate emulsion copolymers}

\section{Citation for published version (APA):}

van Doremaele, G. H. J., Herk, van, A. M., \& German, A. L. (1990). Chemical composition distribution of styrenemethyl acrylate emulsion copolymers. Makromolekulare Chemie, Macromolecular Symposia, 35-36, 231-248. https://doi.org/10.1002/masy.19900350115

DOI:

10.1002/masy. 19900350115

Document status and date:

Published: 01/01/1990

\section{Document Version:}

Publisher's PDF, also known as Version of Record (includes final page, issue and volume numbers)

\section{Please check the document version of this publication:}

- A submitted manuscript is the version of the article upon submission and before peer-review. There can be important differences between the submitted version and the official published version of record. People interested in the research are advised to contact the author for the final version of the publication, or visit the $\mathrm{DOI}$ to the publisher's website.

- The final author version and the galley proof are versions of the publication after peer review.

- The final published version features the final layout of the paper including the volume, issue and page numbers.

Link to publication

\section{General rights}

Copyright and moral rights for the publications made accessible in the public portal are retained by the authors and/or other copyright owners and it is a condition of accessing publications that users recognise and abide by the legal requirements associated with these rights.

- Users may download and print one copy of any publication from the public portal for the purpose of private study or research.

- You may not further distribute the material or use it for any profit-making activity or commercial gain

- You may freely distribute the URL identifying the publication in the public portal.

If the publication is distributed under the terms of Article 25fa of the Dutch Copyright Act, indicated by the "Taverne" license above, please follow below link for the End User Agreement:

www.tue.nl/taverne

Take down policy

If you believe that this document breaches copyright please contact us at:

openaccess@tue.nl

providing details and we will investigate your claim. 
CHEMICAL COMPOSITION DISTRIBUTION OF STYRENE-METHYL ACRYLATE EMULSION COPOLYMERS

G.H.J. van Doremaele*, A.M. van Herk, A.L. German

Laboratory of Polymer Chemistry, Eindhoven University of Technology, P.O. Box 513, 5600 MB Eindhoven, The Netherlands

Abstract: Thin layer chromatography with flame ionisation detection (TLC/FID) was applied to determine the chemical composition distribution (CCD) of styrene-methyl acrylate (S-MA) emulsion copolymers. The reliability of this method was determined using a weil defined high conversion S-MA solution copolymer. The influence of conversion and monomer water ratio on the emulsion copolymer CCD could successfully be described by a model that uses $r$ values determined in solution, and takes into account the monomer partitioning. The samples were prepared in the presence of 1-dodecanethiol in order to reduce the molecular mass of the copolymer formed. Not only the conversion part of the total copolymer CCD but also the instantaneous (statistical) part appeared to be important.

\section{INTRODUCTION}

Recently, much attention has been paid to the development of models that describe emulsion copolymerization kinetics (Refs.1-7) and the molecular microstructure of emulsion copolymers in terms of sequence distribution (Refs.1,8) and (molar mass) chemical composition distribution ((MM) CCD) (Refs.8-12). From existing theories it appears that in general the (MM) CCD significantly deviates from the one expected on the grounds of the classical copolymerization kinetics in bulk or solution processes, due to the heterogeneity of the emulsion copolymerization system. Experimental determination of emulsion copolymer microstructure is a prerequisite for the verification and thus the applicability of these models. 
Besides kinetic measurements, determination of the copolymer molecular microstructure can be regarded as another tool in modelling the emulsion copolymerization process itself, because the copolymer microstructure directly reflects the microscopic kinetics that take place during emulsion copolymerization. The chemical heterogeneity of the copolymer formed is due to the well-known composition drift of the monomers during reaction in combination with the statistical character of the monomer addition process. Several techniques were described in literature to analyse this chemical composition distribution ( $\mathrm{CCD}$ ), e.g. solvent/non solvent fractionation (Ref.13), DSC (Ref.8), and chromatographic techniques such as adsorption liquid chromatography (ALC) (Refs.14,15), high performance precipitation chromatography (HPPLC) (Ref.16), conventional thin layer chromatography (TLC) (Refs.17,18) and thin layer chromatography / flame ionisation detection (TLC/FID) (Refs. 19-24).

However, these techniques cannot be regarded as standard yet and are still being developed, mostly using bulk or solution copolymers. Unfortunately, hardly any attention has been paid to the experimental CCD determination of emulsion copolymers (Ref.24). TLC of random copolymers is based on adsorption differences and is useful for the elucidation of the CCDs of copolymers with monomeric units that differ in polarity e.g. styrene-(meth) acrylates. The CCDs of these kinds of copolymers have been studied by e.g. Teremachi (Refs.14,17,22), Inagaki (Ref.18) and Tacx (Refs.23,24). In this paper the TLC/FID technique was applied to styrene-methyl acrylate emulsion copolymers to give experimental verification of the copolymer CCD model predictions. Accuracy and reliability of the TLC/FID technique were determined by means of calibration using both low and high conversion solution copolymers.

\section{EXPERIMENTAL SECTION}

Purification of chemicals

styrene (S) (Merck) and methyl acrylate (MA) (Merck) were distilled under nitrogen at reduced pressure. The initiator, potassium persulfate (Merck p.a.), the chain transfer agent, 1-dodecanethiol (Fluka for synthesis), the emulsifier, sodium dodecyl sulfate (SDS) (Fluka puriss), and the solvent toluene were used without further purification. The water was distilled twice. The initiator, 2,2-azoisobutyronitrile (AIBN) (Fluka p.a.) was recrystallized once from methanol.

Preparation of reference copolymers by solution copolymerization

The reference copolymers required for calibration and determination of the reliabitity and accuracy of the TLC/FID method to determine the emulsion copolymer CCD, were prepared under nitrogen atmosphere by low conversion $(<10 \%)$ solution polymerization in toluene in a 1 litre glass vessel, thermostated at $335 \mathrm{~K}$.

The total monomer concentration was $3 \mathrm{~mol} / 1$ and the AIBN concentration was $8 \mathrm{mmol} / \mathrm{l}$. The total conversion and monomer feed ratio were measured by means of GLC. The solution copolymers were isolated and purified by pouring the reaction mixture out in a 15 fold excess of cold hexane. The final products were dried at $328 \mathrm{~K}$ in a vacuum stove for at least 6 $\mathrm{h}$ at $10^{-1}$ Torr and finally for $8 \mathrm{~h}$ at $10^{-5}$ Torr. 
Emulsion copolymerization and copolymer purification procedure

The emulsion copolymerizations were carried out under nitrogen atmosphere in a 1 litre glass vessel thermostated at $323 \mathrm{~K}$. The monomers in which 1-dodecanethiol was dissolved were added dropwise to the SDS solution in water. When the emulsion reached reaction temperature a potassium persulfate solution in water was added to the reaction mixture.

overall monomer concentrations during the entire course of the reaction were monitored by means of on line GLC. Total weight conversion was checked by means of dry solid analysis. The emulsion copolymers were purified from SDS and unreacted potassium persulfate, monomers and 1-dodecanethiol by careful coagulation with an aluminium nitrate (Merck cryst. pure) solution $(0.001 \mathrm{~mol} / 1)$. The copolymers were thoroughly washed at least ten times with hot water followed by filtration. Finally, the copolymers were dried at $328 \mathrm{~K}$ at $10^{-5}$ Torr for at least $24 \mathrm{~h}$.

\section{TLC/FID}

The chromarods (Iatron lab. type $S$ ) were activated in a vacuum stove at $393 \mathrm{~K}$ and subsequently scanned twice. In order to obtain accurate copolymer CCD analysis by means of TLC/FID it is extremely important that the sample $(0.2 \mu 10.18 \mathrm{w} / \mathrm{v})$ is spotted on the rod very accurately with a syringe resulting in little spot broadening. Furthermore, after spotting, in contrast to common practice in TLC when low-molecular-mass samples are analysed, the rods were not dried prior to elution. Spotting and elution under a solvent saturated atmosphere avoids precipitation of the copolymer on the rods and thus the copolymer will stay in dynamic equilibrium with solvent and adsorbent. Without these precautions, precipitation of the copolymer occurs prior to elution or during elution, and as a result of slow redissolution this leads to an apparent $\mathrm{CCD}$.

A few ( 2 to 4 ) of the ten rods in the metal frame were not spotted with samples to analyse, but with a mixture of well defined reference copolymers, i.e. homogeneous copolymers prepared by means of low conversion solution copolymerization. The $R_{f}$ values of the reference copolymers were used to calibrate the chromatograms of the unknown samples. A correction was made accounting for small differences in the elution front distances of the ten different rods. However, these differences were minimised $(<3 z)$ by selecting rods that show the same elution rate behavior. For MA rich copolymer samples, reference copolymers were taken with copolymer compositions, in terms of styrene fractions of $0,0.12,0.33$, $0.46,0.57$ and 0.76 . In case of $\mathrm{S}$ rich copolymers, reference compositions were $0.46,0.57,0.76,0.81$ and 1 . All reference copolymers had molar masses of approximately $M_{n}=40000$ $(g / \mathrm{mol})$.

A gradient elution technique was applied by adding polar liquids to a rather apolar starting eluant during elution. In order to prevent precipitation of the copolymers during elution leading to a molecular mass dependence of the retardation factor $\left(R_{f}\right)$, (resulting in an apparent $C C D$ ) the copolymers were eluted permanently under saturated solvent conditions. This appeared to be a prerequisite for a molar mass independent retardation factor. Any possible molar mass dependency could easily be checked by comparing the $\mathrm{R}_{\mathrm{f}}$ values of several copolymers with the same chemical composition but with different molar mass. In order to minimize peak broadening and to obtain optimal separation, the elution procedure was adapted to the copolymer composition. For MA rich S-MA copolymers, after an equilibration time of 15 minutes in $25 \mathrm{ml}$ toluene, elution was started by adding $75 \mathrm{ml}$ toluene in the special development tank described by Tacx (Ref.24). After $1,2,3$ and $4 \mathrm{~cm}$ eluant front positions were reached, each time $5 \mathrm{mI}$ acetone was added to the eluant. At 5 and $6 \mathrm{~cm} 10 \mathrm{ml}$ acetone and finally at 7 and $8 \mathrm{~cm} 5 \mathrm{ml}$ methanol was added. Elution was allowed to continue until $9 \mathrm{~cm}$. 
This procedure resulted in an excellent separation

in the MA rich area including pure PMA, which migrated also $\left(R_{f}=0.05-0.1\right)$.

For styrene rich S-MA copolymers a different elution procedure was used, starting with $85 \mathrm{ml} \mathrm{CCl}_{4}$ (by adding $60 \mathrm{ml}$ to the 25 $\mathrm{ml} \mathrm{CCl}_{4}$ used for the 15 minutes equilibration) and adding 10 $\mathrm{ml}$ toluene at 1 and $2 \mathrm{~cm}$ elution front positions, followed by adding each time $5 \mathrm{ml}$ acetone at 4, 5, 6 and $7 \mathrm{~cm}$. After $8 \mathrm{~cm}$ the elution was stopped.

After elution the rods were dried in a vacuum stove at $393 \mathrm{~K}$ for $30 \mathrm{~min}$. For detection the TLC/FID scanning apparatus Iatroscan TH-10 mark III was used, connected to a Carlo Erba amplifier type EL-480 for improved linearity. The optimal conditions for complete detection and minimal rod damage were $1 \mathrm{~atm} . \mathrm{H}_{2}$ pressure, an air flow rate of $1800 \mathrm{~cm}^{3} / \mathrm{min}$, and a scanning speed of $0.42 \mathrm{~cm} / \mathrm{s}$. The influence of copolymer composition on the FID response was investigated and appeared to be very small in this case.

A small peak present in the chromatogram corresponding to copolymer material that had remained on the spotting place, was always less than $5 \%$ of the total peak areas. This small peak was neglected in the $\mathrm{CCD}$ calculations. The average copolymer compositions, as determined from the measured CCD's were verified by means of ${ }^{1} \mathrm{H}$ NMR.

Tacx (Ref.24) has shown that the TLC/FID method failed for emulsion copolymers prepared in the presence of certain emulsifiers (Antarox CO-880 and RE-610), probably due to chemical bonding of emulsifier to the polymer chains during polymerization. However, well purified, emulsion copolymers prepared in the presence of SDS could be analysed very well. Generally, the inaccuracy in the average copolymer composition determined by means of TLC compared with ${ }^{1}$ H NMR was less than 3 molo styrene.
Model calculations

The emulsion copolymer model CCDs were calculated, assuming the ultimate model to be valid for predicting the copolymer microstructure, using "solution" r-values in combination with the local monomer concentrations inside the latex particles (Ref.25). It is assumed that the contribution of aqueous phase polymerization to the total amount of polymerization is negligible. The monomer partitioning between latex particles, aqueous phase and monomer droplets was taking into account [calculated assuming the monomer concentrations to be at equilibrium using emperically determined relations]. The monomer ratio inside the droplets is equal to the monomer ratio in the latex particles, that are swollen with monomer to a concentration of $5(\mathrm{~mol} / 1)$ in stage II. The styrene concentration in the water phase $(<3.5 \mathrm{mmol} / \mathrm{l})$ can be neglected and the methyl acrylate concentration in the water phase is $0.616 f_{m a}(\mathrm{~mol} / 1)$, where $f_{m a}$ is the mol fraction methyl acrylate inside the monomer droplets.

From the individual polymerization rates of both monomers, one can calculate the average instantaneous copolymer composition at each conversion. Integration over conversion provides the conversion part of the total CCD. The instantaneous (statistical) part of the total CCD of the copolymer is calculated by modified stockmayer equations $\left(W_{1}{ }^{\prime}(y)\right.$ ) (eq. 1 and 2) (Refs.26,27), that were originally derived for bulk and solution copolymers. The use of these equations is possible because the statistical processes on molecular level that determine the monomer additioning are independent of the type of process (i.e. bulk, solution or emulsion copolymerization). Therefore, homogeneous solution and emulsion copolymers with the same MMD and average chemical composition must have the same (instantaneous) $\mathrm{CCD}$ as long as (Co)polymerization in the water phase or at interface plays no significant role. 
The relative mass $\left[w_{1}^{\prime}(y) d y\right]$ of macromolecules having length $l$ and compositions between $\bar{x}_{a}+y$ and $\bar{x}_{a}+y+d y$ is given by equations (1) and (2) (Ref.27).

$$
w_{1}(y)=K \exp \left\{\frac{-l y^{2}}{2 \bar{x}_{a}\left(1-\bar{x}_{a}\right) k}\right\}
$$

$$
w_{1}^{\prime}(y)=w_{1}(y) \quad\left\{1+\frac{Y(1-D)}{D+\bar{x}_{a}(1-D)}\right\}
$$

\section{where}

$\mathrm{K}=\exp (-l / \lambda) \quad l / \lambda^{2}\left(l / 2 \pi \overline{\mathrm{x}}_{\mathrm{a}}\left(1-\overline{\mathrm{x}}_{\mathrm{a}}\right) \mathrm{k}\right)^{0.5}$

$k=\left\{1-4 \bar{x}_{a}\left(1-\bar{x}_{a}\right)\left(1-r_{a} r_{b}\right)\right\}^{0.5}$

$\mathrm{D}=\mathrm{M}_{\mathrm{b}} / \mathrm{M}_{\mathrm{a}} \quad$ : ratio of the molecular masses of both monomers

$y=x_{a}-\bar{x}_{a}:$ difference in chemical composition between a single copolymer molecule and the average composition

$w_{1}(y)$ : stockmayer distribution function of copolymer molecules with degree of polymerization $l$ for the chemical composition

$W_{1}{ }^{\prime}(y): W_{l}(y)$, modified for different monomer molecular masses

$\lambda:$ number average degree of polymerization

$l$ : degree of polymerization

\section{RESULTS}

Verification of the applicability of the TLC/FID method used, by analysing solution copolymers

In Figure (1) the experimental $\mathrm{CCD}$ of a high conversion solution S-MA copolymer $\left((S / M A)_{0}=0.85\right.$; conversion $=97$ molf $)$ is compared with the model $\mathrm{CCD}$, calculated using the modified Stockmayer equation proposed by Tacx (Ref.27). The model CCD was calculated accounting for both the composition drift and the instantaneous heterogeneity due to the statistical character of the monomer addition process. Furthermore, the model takes into account the difference in molar mass between the two monomers.

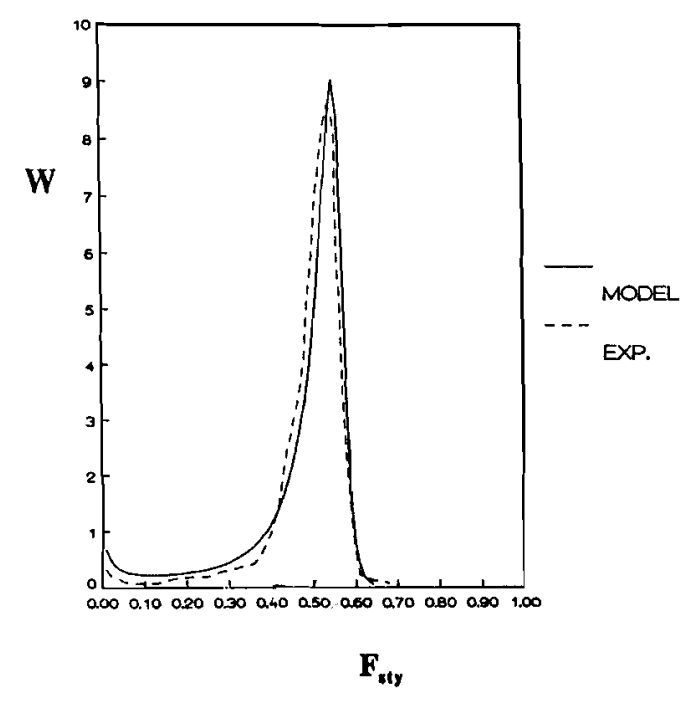

Fig.1. CCD of a high conversion solution styrene-methyl acrylate copolymer.

$(\mathrm{S} / \mathrm{MA})_{0}=0.85 ;$ conv. $=97 \mathrm{~mol} ; \mathrm{M}_{w}=65000(\mathrm{~g} / \mathrm{mol})$ 
The bulk copolymerizations

In the model calculations of the emulsion copolymerization it is assumed that solution $r$ values $\left(r_{s}=0.73, r_{m a}=0.19\right)$ can be used to describe the copolymerization behavior inside the latex particles, where local copolymer concentrations are high. In order to verify that the $r$ values remain unaffected, some bulk copolymerization experiments were carried out to determine the sensitivity of the $r$ values to the viscosity, i.e. to any possible diffusion limitation in the propagation steps. Such an effect might result in a drift of both $r$ values towards unity. Styrene and methyl acrylate were copolymerized till low conversion $(<1 \%)$ in the presence of polystyrene (PS) $(\mathrm{Mw}=42000 \mathrm{~g} / \mathrm{mol})$ at $323 \mathrm{~K}$ (Table (1)) and after the (co) polymer was isolated and purified, the copolymer was analysed by means of the calibrated TLC/FID. This technique appeared to be extremely useful because the chemical composition of the very small amount of copolymer, even in the presence of an excess of pure PS, could be analysed very well as appeared from the two well separated peaks. The results shown in Table (2) indicate unambiguously that the $r$ values remain unaffected in the latex particles at least during stage II of the emulsion copolymerization.

Tab.1. Recipe (in grams) of prelimary bulk copolymerizations

\begin{tabular}{lcc}
\hline & A & B \\
\hline S & 1.40 & 0.55 \\
MA & 2.93 & 1.88 \\
PS & 4.31 & 2.02 \\
AIBN & 0.02 & 0.02
\end{tabular}

Tab.2. Experimentally determined average chemical composition of bulk S-MA copolymers prepared in the presence of PS, compared to model calculations

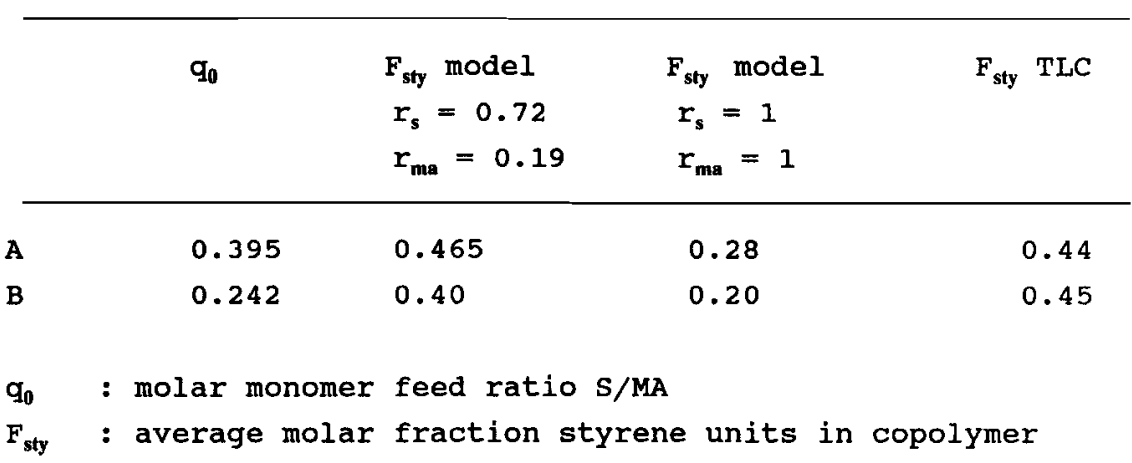

Emulsion copolymer results

Due to the different water solubility of MA and $S$ the occurrence and composition of an azeotropic monomer feed in the emulsion copolymerization depends on the overall monomer water ratio (Refs.25, 28,30,31). For instance, using an overall monomier feed ratio of $(S / M A)_{0}=3(\mathrm{~mol} / \mathrm{mol})$ and a monomer water ratio of $\mathrm{M} / \mathrm{W}=0.2(\mathrm{~g} / \mathrm{g})$, only little composition drift during emulsion copolymerization is noticed. Therefore, the copolymer formed is expected to be homogeneous. In Figure (2) the experimental and model CCD of this emulsion S-MA copolymer have been plotted. From Figure (2) it can be concluded that at least up to 90 mol\% conversion the copolymer formed under these conditions is homogeneous with respect to the chemical composition. 


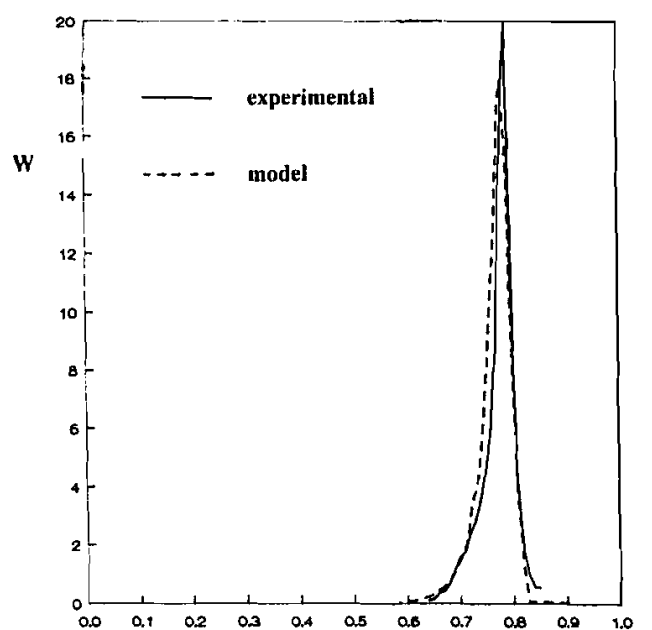

$\mathbf{F}_{\text {tw }}$

Fig.2. CCD of an emulsion styrene-methyl acrylate copolymer prepared under almost azeotropic conditions.

$(\mathrm{S} / \mathrm{MA})_{0}=3(\mathrm{~mol} / \mathrm{mol}) ; \mathrm{M} / \mathrm{W}=0.2(\mathrm{~g} / \mathrm{g}) ; \mathrm{conv} .=90 \mathrm{~mol} \% ;$ $M_{w}=160000(g / m o l)$

Under the same reaction conditions but using a different recipe, other interesting CCDs can be obtained. In Figure (3) three experimentally determined CCDs of an emulsion copolymer prepared under $(\mathrm{S} / \mathrm{MA})_{0}=0.33(\mathrm{~mol} / \mathrm{mol})$ and $\mathrm{M} / \mathrm{W}=0.5(\mathrm{~g} / \mathrm{g})$ at different conversions are shown. The area under the

distribution curve has been taken proportional to the conversion. The difference in chemical composition of the copolymer peak at approximately 45 styrene is probably due to the experimental inaccuracy. The peak broadening, due to spotting and elution, of pure PMA, present in the sample, together with the direct use of the calculated TLC calibration curve, results into calculated but physical impossible negative styrene fractions. The extent to which the TLC peak broadening determines the extra broadening in the calculated CCD, strongly depends on the slope of the calibration curve, which was poor for pure homopolymer PMA under the experimental conditions.

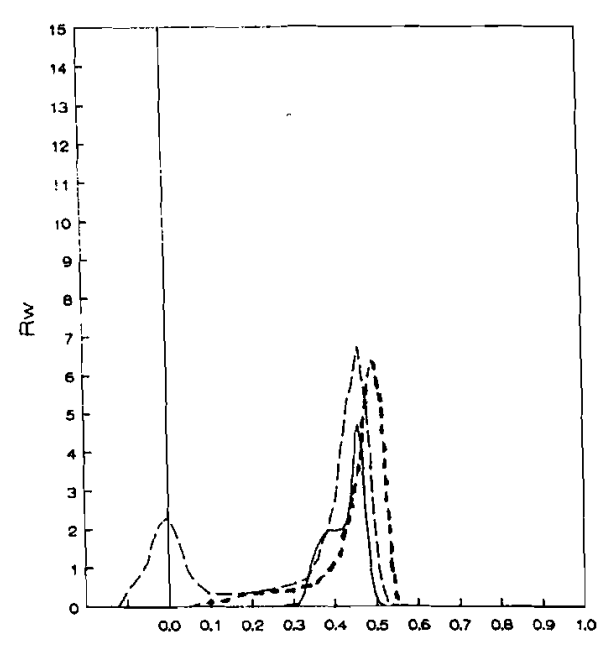

Fsty

Fig.3. Experimental CCDs of SMA emulsion copolymers cumulatively obtained at different conversion levels : (-):36 mol\%, (- - -) $64 \mathrm{~mol} \%,(---): 95 \mathrm{~mol} \%$.

$(\mathrm{S} / \mathrm{MA})_{0}=0.33 ; \mathrm{M} / \mathrm{W}=0.2 ; \mathrm{M}_{w} \approx 100000(\mathrm{~g} / \mathrm{mol})$

Neglecting water phase polymerization $(<1 \%)$ (Refs.7,29) the monomer ratio inside the latex particles during emulsion copolymerization together with the r-values determines the instantaneous average copolymer composition. Here, the local monomer ratio differs from the overall monomer feed ratio in the latex. So the latex particles will be more styrene rich as compared with the overall monomer ratio. Therefore, the initial copolymer formed will also be richer in styrene as compared with the expectations based on the well known instantaneous copolymerization equation without taking into account the monomer partitioning. This results in a strong composition drift during polymerization towards compositions containing the more water soluble monomer, i.e. MA, and 
eventually leading to a non-negligible amount of polymerization of pure MA at the end of the emulsion copolymerization.

Changing the monomer/water ratio one would expect qualitatively a similar behavior but quantitatively another extent of the buffer capacity for MA in the water phase. Very clearly this effect is illustrated in Figures (4) and (5). where both experimental (Fig. 4) and model (Fig. 5) CCDs are shown of S-MA copolymers, that were prepared using the same initial overall monomer feed ratio but different monomer/water ratios.

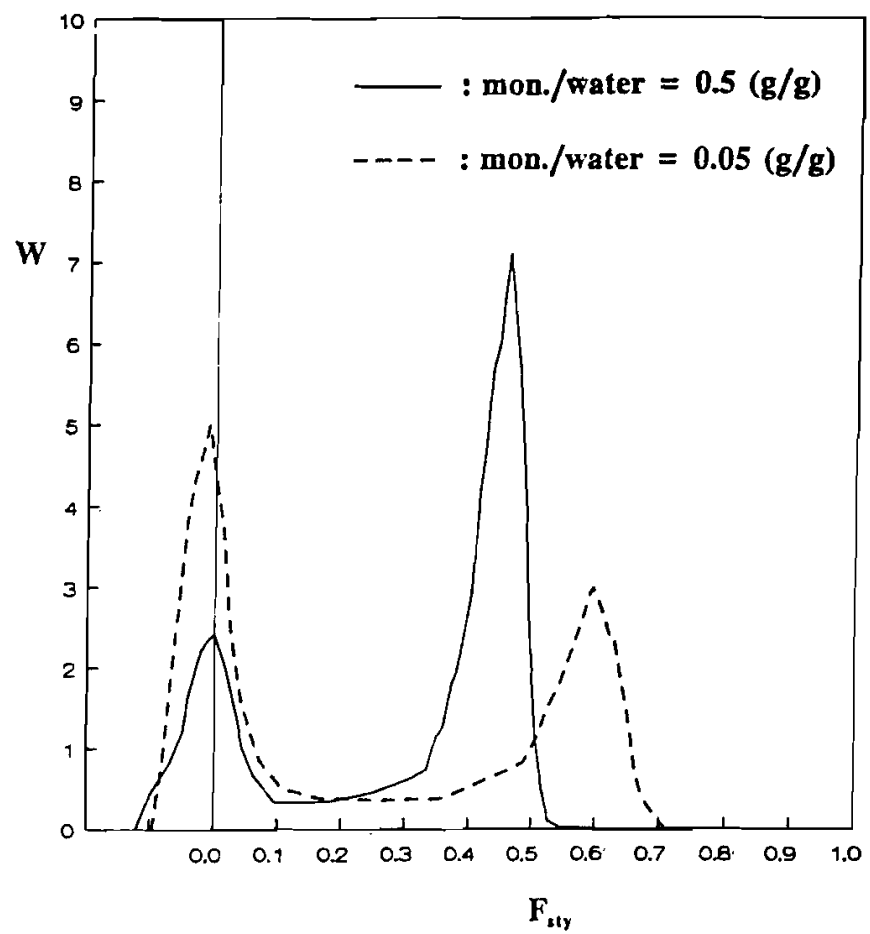

Fig.4. Experimental CCDs of two emulsion SMA copolymers prepared at the same monomer ratio $\left((\mathrm{S} / \mathrm{MA})_{0}=0.33(\mathrm{~mol} / \mathrm{mol})\right)$, but at different monomer/water ratios. (conv. $=95$ molq)
It is clearly shown that using a lower monomer/water ratio the 'copolymer peak' is more styrene rich. For mass balance reasons, the average copolymer composition at high conversion must be $F_{\text {uy }}=0.25$, so a lower monomer,water ratio should result in the formation of more pure PMA at the end of the emulsion copolymerization.

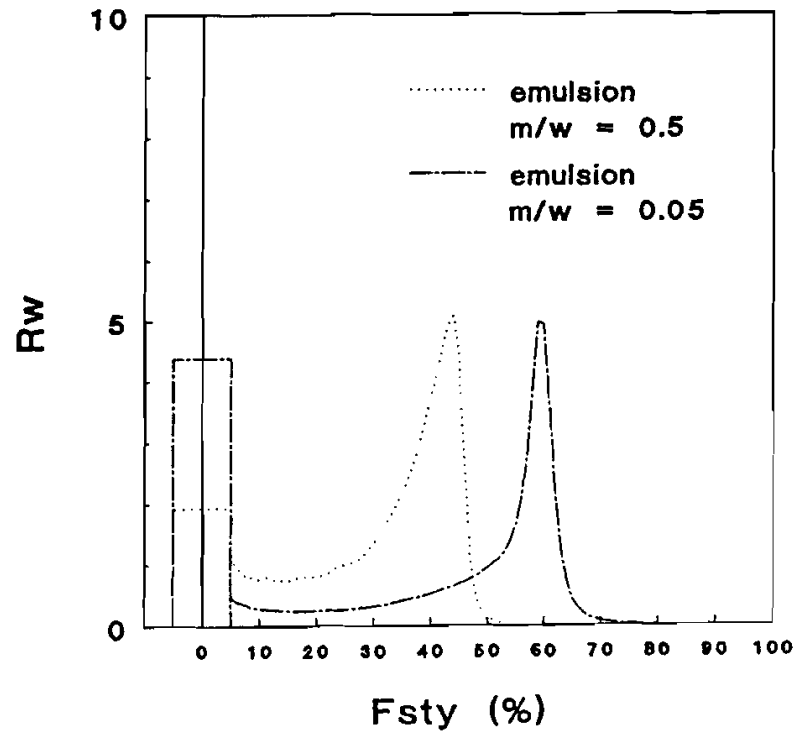

Fig.5. Model CCDs of two emulsion SMA copolymers prepared at the same monomer ratio $(\mathrm{S} / \mathrm{MA})_{0}=0.33(\mathrm{~mol} / \mathrm{mol})$ but at different monomer/water ratios. (conv. $=95 \mathrm{~mol}$ ) 
REFERENCES

Copolymer analysis by means of TLC/FID is a powerful tool in the experimental verification of the theoretical $\mathrm{CCD}$ predictions of copolymers in which the two kinds of monomer units differ moderately in polarity. The model was successfully applied to styrene-methyl acrylate batch emulsion copolymerization. The effects on copolymer microstructure of different water solubility of the monomers in combination with varying monomer water ratios were correctly predicted by the model as well as experimentally verified by means of TLC/FID.

\section{ACKNOWLEDGEMENT}

The authors thank ir. L.J. aan de Meulen for performing many TLC experiments. This investigation was supported by the Netherlands Foundation for Chemical Research (SON) with financial aid from the Netherlands organization for Scientific Research (NWO). (1985) (1988) (1989)
1) M.J. Ballard, D.H. Napper, R.G. Gilbert, J. Polym. Sci., Polym. Chem. Ed. 19, 939 (1981)

2) J.R. Richards, J.P. Congalidis, R.G. Gilbert, J. Appl. Polym. Sci. 37, 2727 (1989)

3) M. Nomura, K. Fujita, Makromol. Chem.. Suppl. 10/11, 25

4) E.P. Dougherty, J, Appl, Polym. Sci. 32, 3051 (1986)

5) E.P. Dougherty, J, Appl. Polym. Sci. 32, 3079 (1986)

6) R.N. Mead, G.W. Poehlein, Ind. Eng. Chem. Res. 27, 2283

7) R.N. Mead, G.w. Poehlein, Ind. Eng. Chem. Res. 28, 51

8) W. Ramirez-Marquez, PhD Thesis, University claude Bernard, Lyon (1987)

9) G. Lichti, R.G. Gilbert, D.H. Napper, J. Polym. Sci,' Polym. Chem. Ed. 18, 1297 (1980)

10) G. Storti, S. Carra, M. Morbidelli, G. Vita, J. Appl. Polym. Sci. 37, 2443 (1989)

11) E. Giannetti, G. Storti, M. Morbidelli, J. Polym. Sci., Part A : Polym. Chem. Ed. 26, 1835 (1988)

12) E. Giannetti, G. Storti, M. Morbidelli, J. Polym. Sci. Part A : Polym. Chem. Ed. 26, 2307 (1988)

13) G. Riess, P. Callot, "Fractionation of copolymers" in Fractionation of synthetic polymers, id. L.H. Tung, Marcel Dekker, New York 1977

14) S. Teramachi, A. Hasegawa, Y. Shima, M. Akatsuka, M. Nakajima, Macromolecules 12,992 (1979)

15) M. Danielewicz, M. Kubin, J. Appl. Pol. Sci. 26, 951 (1980)

16) G. Glöckner, "Analyses of Compositional and structural Hetrogeneities of Polymers by Non-Exclusion Chromatography", Adv. in Polym. Sci, 79 (1986)

17) S. Teramachi, A. Hasegawa, S. Yoshida, Macromolecules 16, 542 (1983) 
18) H. Inagaki, H. Matsuda, F. Kamiyama, Macromolecules 1 , 520 (1968)

19) T. Ogawa, W. Ishitobi, J. Polym. Sci., Polym. Chem. Ed. 21, 781 (1983)

20) F.B. Padley, J. Chromatogr. 39, 37 (1969)

21) H. Inagaki, T. Tanaka, pure Appl. Chem. 54, 309 (1982)

22) S. Teramachi, A. Hasegawa, N. Uchiyama, J. Polym. Sci., Polym. Lett. Ed. 22, 71 (1984)

23) J.C.J.F. Tacx, J.L. Ammerdorffer, A.L. German, Polymer $\underline{29}, 2087$ (1988)

24) J.C.J.F. Tacx, A.L. German, J. Polym. Scj Part A : polym. Chem. Ed. 27, 817 (1989)

25) J. Guillot, Makromol. Chem., Suppl. 10/11, 165 (1985)

26) W.H. Stockmayer, J. Chem. Phys, 13, 199 (1945)

27) J.C.J.F. Tacx, H.N. Linssen, A.L. German, J. Polym, Sci., Polym. Chem. Ed. 26, 61 (1988)

28) J. Guillot, in "Future Directions in Polymer Colloids", va. M.S. El-Aasser, R.M. Fitch, Martinus Nijhof Publishers, 65, 1987

29) M. Nomura, U.S. Satpathy, Y. Kouno, K. Fujita, J, Polym. Sci.: Part C : Polym. Lett. Ed. 26, 385 (1988) 